\title{
Mechanisms and Molecules of Neuronal Wiring: A Primer
}

\author{
Alex L. Kolodkin ${ }^{1}$ and Marc Tessier-Lavigne ${ }^{2}$ \\ ${ }^{1}$ Solomon H. Snyder Department of Neuroscience at the Howard Hughes Medical Institute, Johns Hopkins \\ University School of Medicine, Baltimore, Maryland 21205 \\ ${ }^{2}$ Genentech, Division of Research, South San Francisco, California, 94080* \\ Correspondence: kolodkin@jhmi.edu and tessier-lavigne.marc@gene.com
}

The complex patterns of neuronal wiring in the adult nervous system depend on a series of guidance events during neural development that establish a framework on which functional circuits can be built. In this subject collection, the cellular and molecular mechanisms that underlie neuronal guidance are considered from several perspectives, ranging from how cytoskeletal dynamics within extending neuronal growth cones steer axons, to how guidance cues influence synaptogenesis. We introduce here some basic topics to frame the more detailed reviews in following articles, including the cellular strategies that define basic themes governing neuronal wiring throughout life, an enumeration of the molecular cues and receptors known to play key guidance roles during neural development, and an overview of the signaling mechanisms that transduce guidance information into growth-cone steering.

$\mathrm{N}_{\mathrm{d}=\mathrm{en}}^{\mathrm{e}}$ erve processes extend toward their immediate and final targets with remarkable precision. At the tip of an extending axon is a flattened, fan-shaped structure called a growth cone, with many long, thin spikes that radiate outward much like fingers on a glove. Classical observations of neuronal growth cones and the formation of axonal and dendritic trajectories during neural development led to the conclusion that extrinsic cues must exist that have the capacity to steer extending neuronal processes. For over 100 years, neuroscientists have searched for these cues, their cell surface receptors, and an understanding of how the cues signal spatial information to the extending neuronal processes to direct neural circuit formation.
A wealth of cellular observations indicate that growth cones are actively directed along their prescribed pathways. In this collection, Raper and Mason review the extensive body of experiments that support this view (Raper and Mason 2010). These studies reveal that neural wiring occurs through a combination of initial neuronal activity-independent guidance events, and that these early formed connections are subsequently refined through electrical signaling among neurons. The cues that initially guide axons and dendrites can function at both long and short ranges, and they are capable of influencing the bundling of axons together into nerves or fascicles (termed "fasciculation") and also of mediating interactions between nerves and the substrates on which they extend

Editors: Marc Tessier-Lavigne and Alex L. Kolodkin

Additional Perspectives on Neuronal Guidance available at www.cshperspectives.org

*Address as of March 2011: Rockefeller University, 1230 York Avenue, New York, New York 10065; email: marctl@rockefeller.edu

Copyright (C) 2011 Cold Spring Harbor Laboratory Press; all rights reserved; doi: 10.1101/cshperspect.a001727

Cite this article as Cold Spring Harb Perspect Biol 2011;3:a001727 


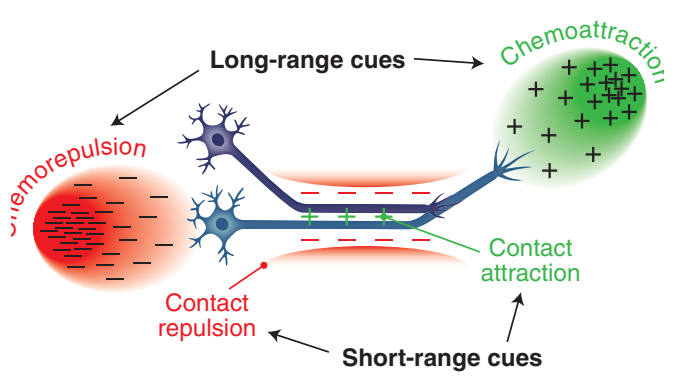

Figure 1. The diversity of neuronal guidance mechanisms. Neuronal processes are guided by cues that can function at long and short distances to mediate either attractive or repulsive guidance.

(Fig. 1). Guidance cues associated with particular intermediate or final targets can be chemoattractive or chemorepulsive, and provide the information essential for selective guidance of distinct neuronal populations. Sequential responses to guidance cues as axons extend over very long distances toward their targets allow for complex pathways to develop, but this often requires that neurons extinguish their responses to certain cues and acquire responsiveness to others at key choice points. Much work over the past several decades has been devoted to identifying these guidance cues and their receptors, and to understanding how cellular responses to these cues change to allow for guidance of extending neuronal processes along discrete segments of their journey to their final targets.

\section{DIVERSITY OF GUIDANCE CUES FOR DEVELOPING NEURONAL PROCESSES}

Determining how neuronal connectivity is established during neural development and regulated during adult life has depended critically on identifying the molecules and signaling events underlying cellular observations of neuronal guidance. Three experimental approaches over the past two decades have identified a wide variety of guidance molecules and their receptors: (1) pairing biochemistry and in vitro tissue culture assays to detect proteins with either attractive or repellent properties; (2) using forward genetics to identify mutations that affect axon trajectories in vivo; or (3) using genetic and tissue culture approaches to characterize the functions of molecules with distributions or molecular structures that make them attractive candidate guidance cues. Using these strategies, four major families of guidance cues (the "canonical cues") with very well-established roles in neuronal guidance have been identified: the Netrins, Slits, Semaphorins, and Ephrins. Other classes of molecules best known in different contexts are also now recognized to function as neuronal guidance cues and include certain morphogens and growth factors. Cell-adhesion molecules (CAMs) of various classes have long been implicated in neuronal guidance, and members of the immunoglobulin (Ig) and cadherin super families play key roles in regulating distinct aspects of neuronal wiring. The identification and characterization of these cues and their receptors have led to several important generalizations about guidance mechanisms, including the existence of short- and long-range guidance cues, the multifunctional nature of several cues, and the evolutionary conservation of many guidance molecules and the roles they perform in neuronal guidance (Tessier-Lavigne and Goodman 1996; Dickson 2002). Do additional classes of guidance cues remain to be discovered? Most certainly they do; however, the known guidance-cue families illustrate major principles of neuronal wiring mechanisms. We review here each of the major families of "canonical" guidance cues, and also morphogens, growth factors, and certain CAMs, with respect to their roles in neuronal guidance and connectivity.

\section{Netrins}

Netrins are a small family of phylogenetically conserved cues of about $70-80 \mathrm{kDa}$. There is one Netrin in Caenorhabditis elegans (UNC6), two in Drosophila (Netrin-A and NetrinB), and two closely related Netrins in mammals (Netrin-1 and Netrin-3; Netrin-2 is present in chicks but not in mammals). These Netrins share homology in their amino-terminal twothirds with the amino-terminal globular domain and first three epidermal growth factor (EGF)-like 
repeats of the $\gamma$ chain of laminins; their carboxy-terminal third is highly basic (Fig. 2). A third mammalian Netrin, Netrin-4 (or $\beta$-Netrin), is more distantly related, having a similar overall structure but showing greater homology to the $\beta$ chain of laminins (Koch et al. 2000).

Netrins were initially identified through convergent studies in C. elegans and in vertebrates. In C. elegans, the unc- 6 gene is required for guidance of axons along the dorso-ventral axis (Hedgecock et al. 1990) and encodes a Netrin (Ishii et al. 1992) that is located at the ventral midline (Wadsworth et al. 1996). In vertebrates, an outgrowth-promoting and chemoattractant activity for spinal commissural axons made by ventral midline floor plate cells (Tessier-Lavigne et al. 1988) was shown to be mediated by Netrin-1 (Kennedy et al. 1994; Serafini et al. 1994) and required for guidance in vivo (Serafini et al. 1996). Netrins are bifunctional, capable of attracting some axons and repelling others (Colamarino and TessierLavigne 1995), explaining how they can guide axons both toward and away from the midline (Wadsworth et al. 1996). Netrins were also found at the nervous system midline in Drosophila, where they contribute to attracting axons to the midline (Harris et al. 1996;

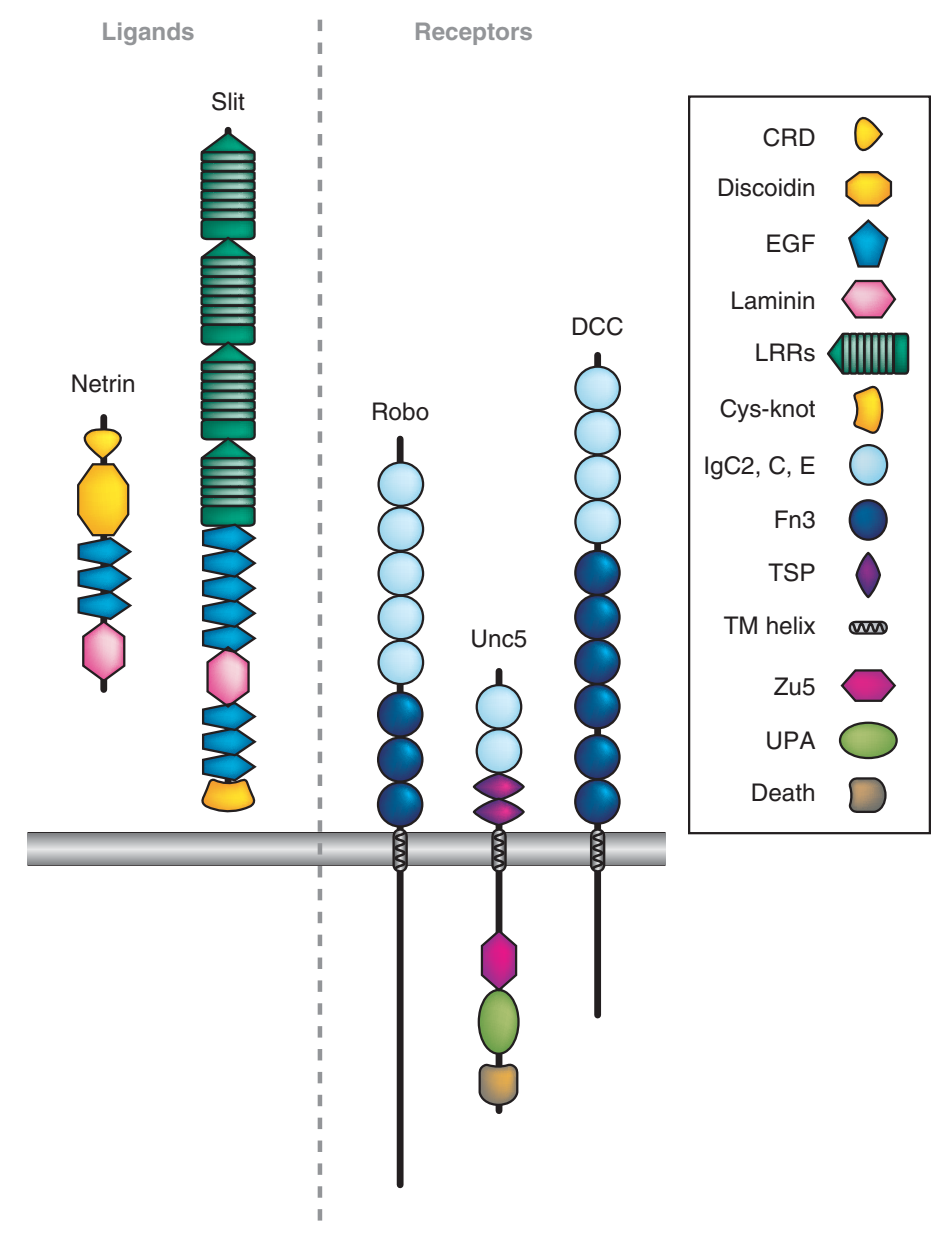

Figure 2. Netrins, Slits, and their receptors. A schematic depicting these cues and their receptors, including receptors required for attraction (DCC) and repulsion (UNC5 for Netrins; Robo for Slits). The key defines distinct molecular domains found in these proteins. 
Mitchell et al. 1996); indeed, Netrins have now been documented to function in axon guidance across the animal kingdom, as described in detail throughout this collection (see also Moore et al. 2007). Importantly, Netrins can function at "long-range," diffusing from their source a few hundred micrometers in some settings (Kennedy et al. 1994; Kennedy et al. 2006), but at "short-range" in others, being immobilized on the cells that make them (Deiner et al. 1997; Brankatschk and Dickson 2006). This illustrates that there is not a hard and fast distinction between long- and short-range guidance systems.

In all species, the attractive effects of Netrins are mediated by receptors of the DCC (Deleted in Colorectal Carcinomas) family, characterized by four immunoglobulin (Ig) and six fibronectin (Fn) type III repeats in their extracellular domains (Fig. 2). Members with well-documented roles in attraction include UNC-40 in C. elegans (Chan et al. 1996), DCC in vertebrates (Keino-Masu et al. 1996), and Frazzled in Drosophila (Kolodziej et al. 1996). A second DCC family member, neogenin, binds Netrin-1 (Keino-Masu et al. 1996) and can mediate some non-neural effects of Netrins (e.g., Srinivasan et al. 2003) but has not yet been clearly implicated in Netrin-mediated axonal attraction. The Ig superfamily member DsCAM (see "Cell-Adhesion Molecules") has been proposed to function as a coreceptor in Netrinmediated attraction in some systems (Andrews et al. 2008; Ly et al. 2008). Repulsive effects of Netrins are mediated by members of the UNC5 family, proteins that possess two Ig and two thrombospondin repeats (Fig. 2) (LeungHagesteijn et al. 1992; Leonardo et al. 1997; Hong et al. 1999; Keleman and Dickson 2001). There is one UNC5 in C. elegans, one in Drosophila, and four (UNC5A-D) in mammals.

\section{Slits}

Slits are large secreted proteins (Fig. 2) that were implicated in axonal repulsion through a search for a midline repellent factor in Drosophila and vertebrates (Brose et al. 1999; Kidd et al. 1999; Li et al. 1999), and through isolation of a branching factor for sensory axons in vertebrates (Wang et al. 1999). Slits possess four aminoterminal leucine-rich repeats, as well as EGF-like repeats and other motifs (Fig. 2). There is one Slit in Drosophila and three (Slit1-3) in vertebrates; a single Slit protein functions in axonal repulsion in $C$. elegans as well (Hao et al. 2001). The repulsive actions of Slit proteins are mediated by receptors of the Robo family (Kidd et al. 1998; Zallen et al. 1998) (Fig. 2), which, similar to DCC and UNC5 family Netrin receptors, are also members of the immunoglobulin superfamily. There are three Robos in Drosophila, three in mammals (a vascular Robo, Robo4, is more divergent), and one (SAX-3) in C. elegans. The branching activity of Slits, observed for both axons and dendrites, is also mediated by Robo family members (Whitford et al. 2002; Ma and Tessier-Lavigne 2007). Some of the $\sim 200 \mathrm{kDa}$ Slits can be cleaved to yield an amino-terminal $\sim 140 \mathrm{kDa}$ fragment that can bind Robos as well (Wang et al. 1999). In vertebrates, the Robo family member Robo3 possesses a splice isoform, Robo3.1, which functions to inhibit the repulsive actions of Robol and Robo2 (Sabatier et al. 2004; Chen et al. 2008). A similar “anti-Robo" function of a Drosophila Robo, Robo2, has been inferred from genetic analysis as well (Spitzweck 2010).

\section{Semaphorins}

The Semaphorins are a large, phylogenetically conserved, protein family that includes both secreted and transmembrane guidance cues (Yazdani and Terman 2006). The first Semaphorin identified was the transmembrane protein grasshopper Semaphorin 1a, originally called "Fasciclin IV" after the name of the monoclonal antibody that defined its neuronal expression pattern, and is a protein required for correct pathfinding of pioneer sensory axons in the developing grasshopper limb (Kolodkin et al. 1992). Sema3A, a secreted Semaphorin originally called "Collapsin-1," was the first vertebrate Semaphorin identified and was found as part of a biochemical purification of factors from brain extracts capable of functioning as axonal repellents in vitro (Luo et al. 1993). There 
are approximately 20 different Semaphorins in higher vertebrates, and all contain a signature Semaphorin domain of approximately 500 amino acids that plays a key role in mediating the association of these proteins with signaling receptors belonging to the Plexin family of receptors (Fig. 3). Semaphorins function in both long-range and short-range guidance.

Most Semaphorins can function as potent inhibitory cues, as shown in a variety of in vitro assays using specific subtypes of cultured neurons and non-neuronal cells. In vivo genetic analyses in invertebrates and vertebrates show conclusively that Semaphorins serve as key repulsive cues during neural development (Tran et al. 2007). For example, mice in which the Sema3A gene has been disrupted by homologous recombination show dramatic axon guidance defects (Kitsukawa et al. 1997). Sema3A is normally expressed in tissues that surround many peripheral nerves and acts as a repellent, constraining motor and sensory neuron projections to their normal trajectories through "surround repulsion." Transmembrane Semaphorins also can function as repellents either in a surround repulsion fashion or, when expressed on axon bundles, to facilitate the unbundling, or defasciculation, of individual axonal processes.

The major receptors for Semaphorins are members of the Plexin family, include nine different proteins in higher vertebrates, and are large phylogenetically conserved transmembrane proteins distantly related to Semaphorins (Fig. 3) (Tamagnone and Comoglio 2000). Many Semaphorins bind Plexins directly, but several secreted vertebrate Semaphorins, including Sema3A, instead bind to the obligate co-receptors Neuropilin-1 or Neuropilin-2; Neuropilins, together with a Plexin receptor, form an active holoreceptor complex. Different secreted Semaphorins require specific combinations of Neuropilin-1 or Neuropilin-2 and a specific Plexin for guidance responses in

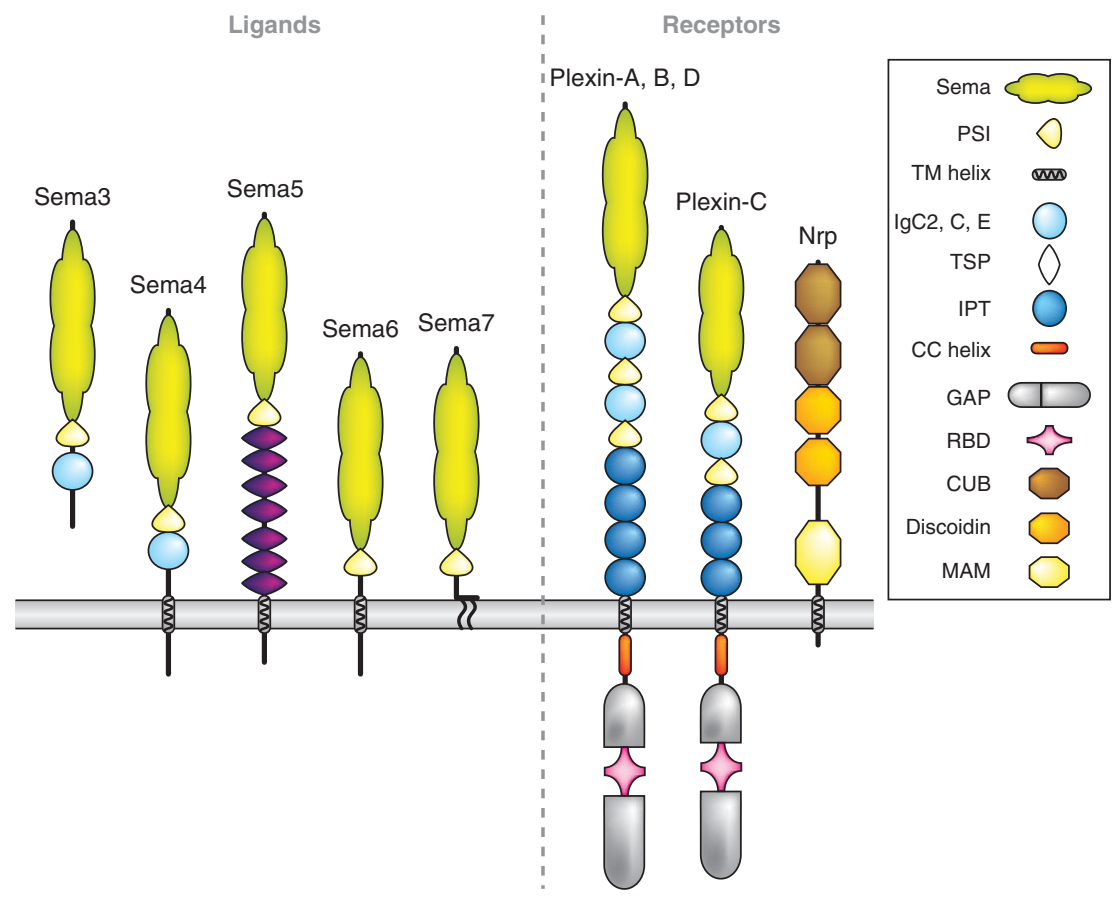

Figure 3. Semaphorins and their receptors. Shown here are the five classes of vertebrate Semaphorins and the major holoreceptor complexes required for Semaphorin-mediated repulsive and attractive guidance responses. Not shown are invertebrate transmembrane class 1 and secreted class 2 Semaphorins, and several non-Plexin/ Neuropilin Semaphorin receptors. The key defines distinct molecular domains found in these proteins. 


\section{A.L. Kolodkin and M. Tessier-Lavigne}

distinct neuronal subtypes, a conclusion drawn from extensive observations both in cell culture and in vivo (Tran et al. 2007).

Plexin receptor activation initiates a series of intracellular signaling events that ultimately results in the local disassembly of growth cone cytoskeletal components and substrate attachments (Zhou et al. 2008). However, many Semaphorins share with proteins belonging to other families of guidance-cue molecules the ability to function as both attractants and repellents, and even the same Semaphorin may under certain circumstances serve in both capacities. This bifunctionality can be directed by use of different holoreceptor complexes or the activation of distinct intracellular signaling pathways. Interestingly, as has been observed for Ephrin guidance cues, transmembrane Semaphorins themselves are also capable of serving as receptors, regulating dendritic targeting events in the Drosophila olfactory system, photoreceptor guidance in the Drosophila visual system, cardiac development in the chicken embryo, and likely thalamic axon guidance in mammals (Tran et al. 2007). Semaphorins facilitate the formation of central and peripheral axon pathways by regulating axon pathfinding and fasciculation. However, they also regulate axon targeting to specific locations of their synaptic partners, pruning of exuberant projections, and the regulation of neuronal morphology and synaptogenesis (Tran et al. 2007). Therefore, Semaphorin signaling via multiple receptors during the establishment and maintenance of neuronal connectivity showcases the versatility of this large and diverse family of molecules.

\section{Ephrins}

The fourth family of canonical guidance cues are the Ephrins, cell-surface signaling molecules that play important roles in a large number of developmental events including axon guidance (Klein 2004). There are two subfamilies; the five class A Ephrins are tethered to the cell surface via GPI linkages, and the three class B Ephrins are transmembrane molecules (Fig. 4). Ephrins must be clustered together to activate their receptors and do not appear to be active if released from the cell surface, so they are thought to function exclusively as short-range guidance cues. These ligands bind receptor tyrosine kinases of the Eph family. Class A Ephrins interact with various degrees of selectivity

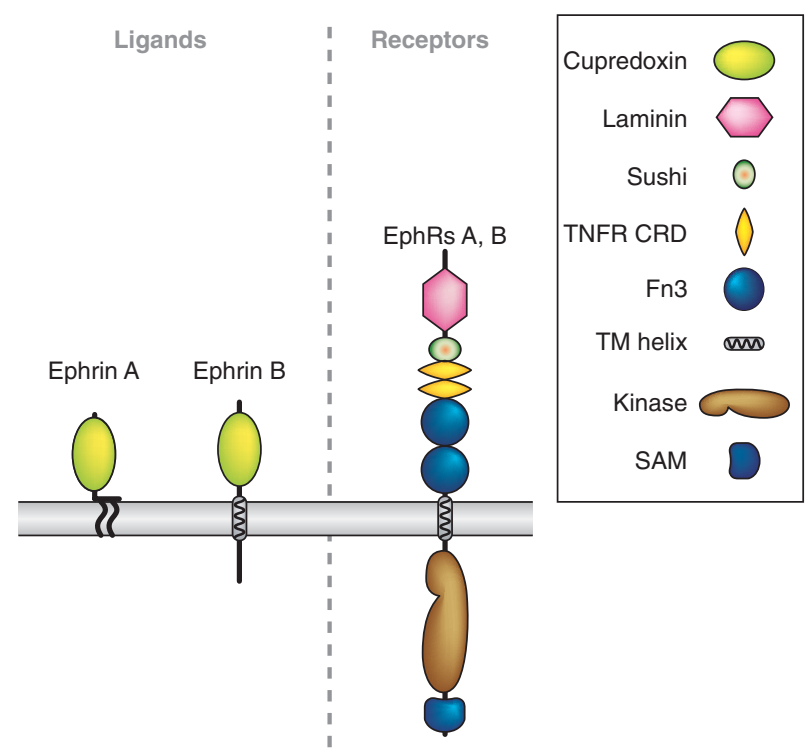

Figure 4. Ephrins and their Eph receptors. A schematic showing the major A and B classes of Ephrins and their EphA and EphB receptors. The key defines distinct molecular domains found in these proteins. 
with eight class A Eph receptors, whereas class B Ephrins interact with six class B Eph receptors (Fig. 4). Ephrins have been shown to play an essential role in organizing topographic projections that connect, for example, retinal ganglion cells in the eye with their target cells in the appropriate portion of the optic tectum in lower vertebrates, or the lateral geniculate nucleus of the thalamus in higher vertebrates (Feldheim and O'Leary 2010, this collection). These mapping functions show the versatility of Ephrins, which can function as attractants for some axons and repellents for other, as well as either positive or negative regulators of axonal branching. In addition to topographic mapping, Ephrins are implicated as short-range attractants and repellents in the guidance of a variety of central and peripheral axons, and have also have roles in the pruning of axonal trajectories. More recent observations indicate that Ephrins and their receptors play key roles in the regulation of dendritic morphology and synaptogenesis in the CNS, implicating Ephrinmediated receptor tyrosine kinase signaling in the regulation of synaptic plasticity (Shen and Cowan 2010, this collection). Ephrins can also participate in "reverse" signaling, functioning as receptors to regulate topographic mapping, axon guidance, and synaptogenesis. Therefore, it is no surprise that the large family of Ephrins and their cognate Eph receptors are found to regulate guidance and cellular morphology in an ever-increasing range of neuronal and nonneuronal cellular contexts.

\section{MORPHOGENS AND GROWTH FACTORS}

While an initial wave of studies in the 1990s was leading to the identification of Netrins, Semaphorins, Ephrins, and Slits as key regulators of axonal attraction and repulsion, parallel studies implicated two other sets of proteins in axon guidance: morphogens of the Wnt, Hedgehog (Hh), and transforming growth factor b (TGFb)/bone morphogenetic protein (BMP) families, as well as a variety of growth factors.

Among the morphogens, Wnts have the most widely described axon-guidance functions. Initial studies showed roles for Wnts in repulsion in Drosophila and attraction in mammals: Drosophila Wnt5, acting via Derailed, the fly homolog of the Ryk receptor tyrosine kinase, was shown to mediate repulsion of axons away from the posterior commissure (Yoshikawa et al. 2003), whereas in mammals a decreasing anterior-to-posterior gradient of Wnt4 was implicated in attracting spinal commissural axons in an anterior direction after midline crossing through the Wnt receptor Frizzled 3 (Lyuksyutova et al. 2003). Since then, roles have been described for several different Wnts in axon attraction and repulsion in diverse neural systems and organisms; roles in guiding neuronal cell migrations, directing topographic mapping in the vertebrate visual system, and in regulating synapse formation have also been described (Salinas and Zou 2008).

Guidance roles for Sonic hedgehog (Shh) in vertebrates have also been described (Charron and Tessier-Lavigne 2007), including being a repellent for a subset of retinal ganglion cells (Trousse et al. 2001) and an attractant for spinal commissural axons (Charron et al. 2003). In both cases, the guidance functions appear to involve a complex of the Shh binding protein BOC, an Ig superfamily member, and the Shh signaling component Smoothened (Fig. 5) (Okada et al. 2006; Sanchez-Camacho and Bovolenta 2008; Fabre et al. 2010). To date, roles for Hh family members in guidance have not been documented outside of vertebrates ( $\mathrm{Hh}$ proteins are found in flies but not worms). $\mathrm{TGFb} / \mathrm{BMP}$ family members have been implicated as chemorepellents for spinal commissural axons, repelling them away from the dorsal midline by activating canonical BMP receptors (Augsburger et al. 1999; Yamauchi et al. 2008). However, other examples of $\mathrm{TGFb} / \mathrm{BMP}$ mediated guidance remain to be described. In C. elegans, the UNC-129 gene product encodes a divergent TGF- $\beta$ family member and is required for certain dorsal axon migrations (Colavita and Culotti 1998), but it does not appear to function directly as a guidance cue, instead functioning to modulate the response of the axons to the Netrin UNC-6 by interacting directly with the Netrin receptor UNC-5 (MacNeil et al. 2009). Therefore, the roles of $\mathrm{Hh}$ and 
A.L. Kolodkin and M. Tessier-Lavigne

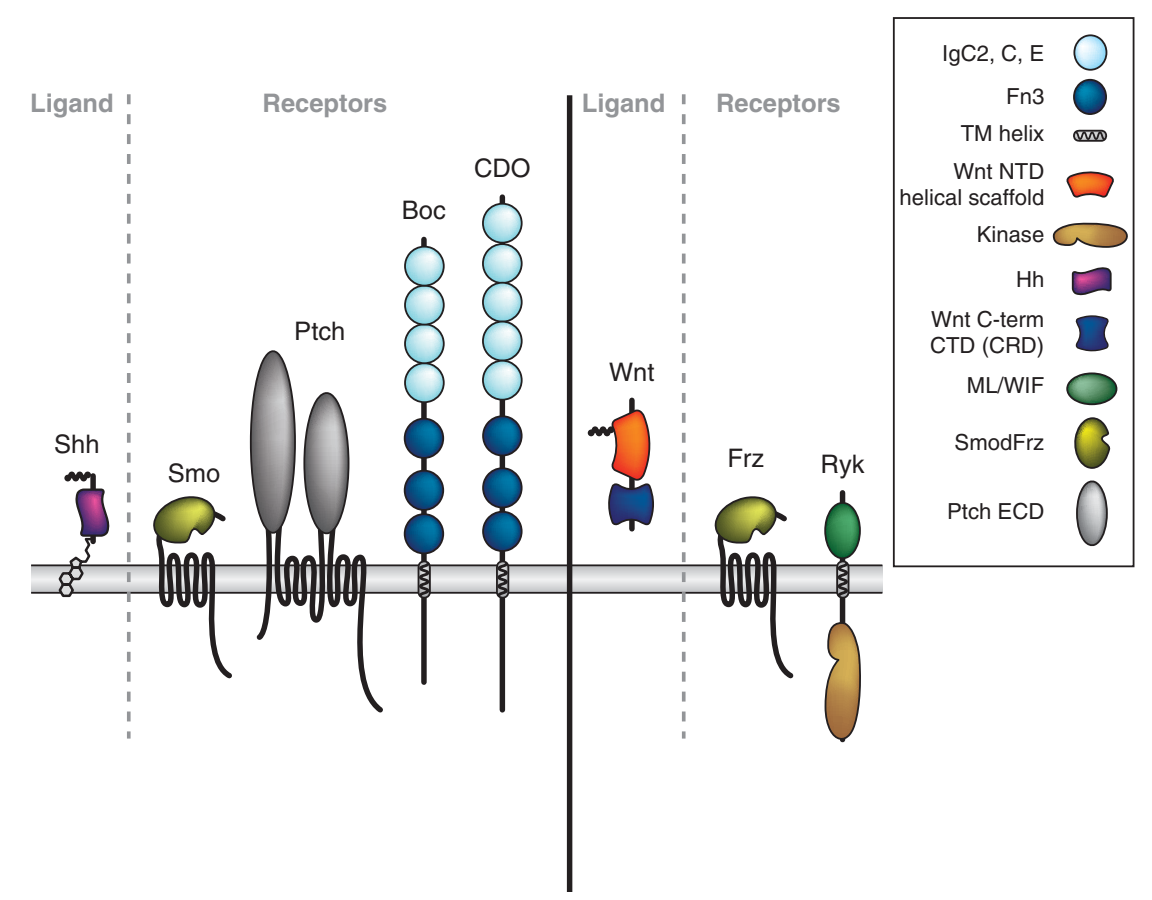

Figure 5. Morphogens involved in neuronal guidance and their receptors. A schematic showing Shh and its receptors (Smo, Ptch, Boc, and CDO), and Wnts and their receptors (Frz and Ryk), all of which serve guidance functions. Not shown are BMPs and their receptors. The key defines distinct molecular domains found in these proteins.

TGF- $\beta$ /BMP proteins in guidance remain to be more fully defined.

A variety of growth factors have also been implicated in attraction of specific populations of axons in the peripheral and central nervous systems of vertebrates. They include hepatocyte growth factor, the neurotrophins brain-derived neurotrophic factor and neurotrophin-3, fibroblast growth factors, glial-derived neurotrophic factor, neuregulin, and stem cell factor (Ebens et al. 1996; O'Connor and Tessier-Lavigne 1999; Kramer et al. 2006; Lopez-Bendito et al. 2006; Shirasaki et al. 2006; Gore et al. 2008). However, the full import of growth factors in axon guidance is poorly understood. To date, the guidance effects have been shown typically only for one set of axons for each growth factor; the growth factors have only been shown to have attractive, not repulsive, effects in vivo; and the effects have mostly been documented in vertebrates. Further studies will be needed to flesh out the roles of growth factors in guidance in general.

\section{CELL-ADHESION MOLECULES}

Before the discovery of the "canonical" guidance-cue families, there had been much interest in the possibility that cell-adhesion molecules (CAMs) of the immunoglobulin or cadherin superfamilies (Fig. 6) play roles in guiding axons. Indeed, a role for homophilic adhesion in regulating axonal fasciculation was documented for the Ig superfamily CAM Fasciclin II (Harrelson and Goodman 1988; Lin et al. 1994; Lin and Goodman 1994). However, when it comes to guidance rather than fasciculation, over the years the idea that such molecules guide through adhesion has been replaced with an emerging focus on the possibility that members of these families might regulate outgrowth stimulation or attraction by 


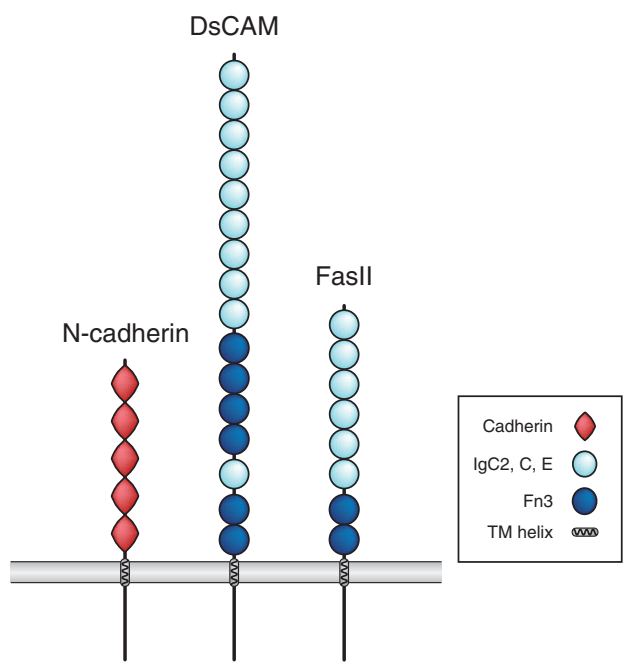

Figure 6. Cell adhesion molecules (CAMs). Shown here are members of two major classes of CAMs: $\mathrm{N}$-cadherin and two members of the Ig superfamily, FasII and DsCAM. The key defines distinct molecular domains found in these proteins.

functioning as signaling molecules, often-but not always-in heterophilic rather than homophilic combinations.

We have already discussed how Ig superfamily members of the DCC and Robo families are guidance receptors for secreted ligands of the Netrin and Slit families. A novel heterophilic guidance pair has been described in Drosophila, where the Ig superfamily member Beaten Path (Beat) functions as a receptor (or receptor component) in motoneurons for the Ig superfamily member Sidestep expressed by intermediate targets, which functions as an attractant for these axons (Siebert et al. 2009). Other Ig CAMs, including NrCAM and L1, have been implicated in guidance in a more indirect role as co-receptors in Semaphorin receptor complexes (Mann et al. 2007).

One of the most fascinating Ig CAMs is Drosophila DsCAM, which is discussed in detail by Grueber and Sagasti in this collection (Grueber and Sagasti 2010). Through alternative splicing, over 19,000 isoforms of DsCAM can be generated (Schmucker et al. 2000). Each isoform can bind to itself, but shows little binding to non-self isoforms; binding of self-isoforms surprisingly mediates repulsion, rather than adhesion or attraction, and is used for axonal and dendrite self-avoidance (Wojtowicz et al. 2007; Hattori et al. 2009).

These and other studies on CAMs illustrate the versatility of Ig superfamily members, and suggest that other ligand-receptor pairs of this family remain to be identified. In the case of cadherins, despite much speculation about their potential functions in guidance, there is little hard evidence for such roles; one example comes from Drosophila, where N-cadherin regulates multiple steps in targeting of axons in the lamina, though how it functions precisely is poorly understood (Nern et al. 2008).

\section{GUIDANCE CUES AND THE CONTROL OF CYTOSKELETAL DYNAMICS}

The key to guidance-cue function in all cell types lies in their ability to transduce extracellular signals into changes in cellular morphology. In developing neurons, this results in directed neuronal growth-cone extension, steering, and also retraction (reviewed extensively in Dent and Gertler 2003; Lowery and Van Vactor 2009). The intrinsic motility of growth cone cytoskeletal components allows for a growth cone to advance and withdraw its filopodia and leading edge. Changes in cytoskeletal dynamics steer growth cones so as to attract or repel them from the source of the cue, and these instructive guidance events are greatly influenced by the degree of growth-cone attachment to the substratum on which they extend. Substrate attachment secures the growth cone, allowing for tension to develop and subsequent growth-cone extension; detachment from the substrate has the opposite effect. Guidance cues can influence growth-cone trajectories by altering the assembly, disassembly, or dynamics of cytoskeletal components. They can also influence substrate adhesion or attachment. Extensive efforts have been devoted to understanding how guidance-cue signaling, acting at any step in this process, directs growth-cones during neural development and also influences growth-cone behavior following injury or degeneration in the adult nervous system. 
Actin and microtubules are segregated within the growth cone such that fibrillar actin (F-actin) is found within the peripheral domain of the growth cone, whereas bundled microtubules occupy the axon shaft and the growth cone central domain. Actin polymerization occurs just behind the leading edge of the advancing growth cone, and actin depolymerization simultaneously occurs in the central domain. In addition, there is a continuous flow of F-actin away from the leading edge and toward the central domain of the growth cone, called "treadmilling," and this retrograde flow is driven by the action of nonmuscle myosin. The recycling of actin monomers generated by depolymerization in the central domain to the leading edge of the growth cone, when balanced by the rate of treadmilling toward the central domain, results in the absence of adhesive contacts with the substratum and little to no net growth-cone advance. However, modulation of F-actin polymerization, depolymerization, or treadmilling by growth-cone guidance-cuesignaling events allows for growth-cone advance, retraction, or if localized to one region of the growth cone, steering. Linkage of F-actin to the substratum through the action of receptors, or receptor complexes, located on the cell surface and capable of associating with both F-actin and extracellular components linked to the substratum, facilitates growth-cone advance through the cessation of net retrograde F-actin flow, and the subsequent advance of the leading edge. A large number of signaling molecules are known to regulate actin dynamics (see Dent et al. 2011 in this collection, for a comprehensive review of this topic). Some of these are actin-binding proteins intimately involved in regulation of actin polymerization, whereas others regulate these proteins through direct interactions or posttranslational modifications. Microtubules (MTs), too, play important roles in growth-cone guidance. Within the growth cone central domain MTs are bundled and mostly stable, but in the peripheral region of the growth cone individual MT polymers are highly dynamic, extending and retracting along F-actin. Stabilization and bundling of these dynamic MTs in regions of growth-cone advance will define where the axon shaft will ultimately form behind the advancing leading edge. Proteins that are capable of altering MT dynamics also provide important avenues for regulation by guidance-cue receptors; therefore, current efforts include characterizing how guidancecue signaling directly influences MT organization in extending and retracting neurons.

Attractive and repulsive guidance cues can influence cytoskeletal dynamics by modulating all of the mechanisms underlying growthcone behaviors. These include regulating Factin and MT assembly or disassembly, the rate of myosin-mediated F-actin translocation, MT dynamic instability, or the attachment of the growth cone to the substratum. Several guidance-cue receptors are known to directly or indirectly regulate members of the Rho family of small GTPases, including Rho, Rac, and Cdc42. These signaling molecules play central roles in regulating actin dynamics, modulating cellular morphology in both neuronal and non-neuronal cells (see Hall and Lalli 2010, this collection). They cycle between inactive GDP-bound and active GTP-bound states through the action of guanine-nucleotideexchange factors (GEFs) and GTPase-activating proteins (GAPs), respectively (Fig. 7). Activation of several distinct classes of guidance-cue receptors can modulate Rho GTPases through the action of multiple distinct adaptor proteins with GEF or GAP activities that associate with these receptors and either stimulate, or inactivate, Rho GTPases. In addition to modulating Rho GTPase activities, guidance-cue receptor activation can also result in signaling events, for example phosphorylation, that in turn allow for the association of signaling-adaptor proteins or kinases that can stimulate signaling cascades with the capacity to regulate cytoskeletal dynamics (see Bashaw and Klein 2010, this collection). Further, guidance-cue receptors are also capable of directly regulating MT dynamics by affecting MT-binding proteins that can inhibit or promote MT polymerization. Taken together, the range of signaling events activated downstream of known guidance-cue receptors provides multiple avenues for regulating the neuronal cytoskeleton and, 
Mechanisms and Molecules of Neuronal Wiring: A Primer

A

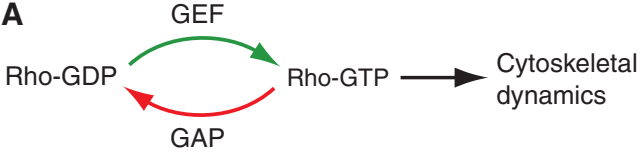

B

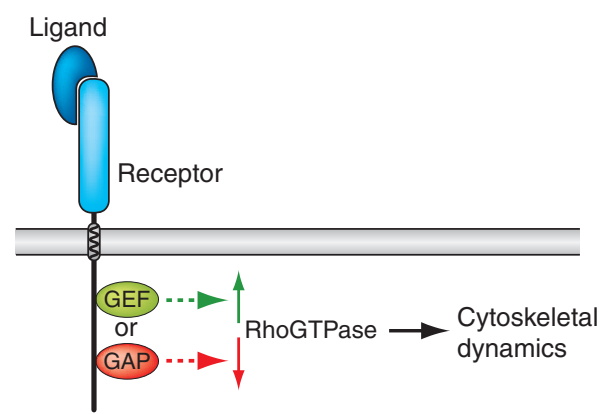

C

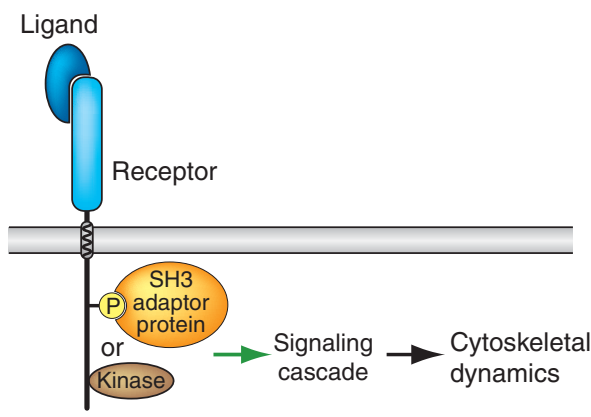

Figure 7. Guidance-cue receptor signaling strategies. (A) Rho GTPases cycle between inactive GDP-bound and active GTP-bound states to regulate cytoskeletal dynamics. (B) Guidance-cue receptor activation can influence Rho GTPase activity through direct associations with GEFs or GAPs. (C) Direct association of activated guidance-cue receptors with other signaling molecules, including signaling-adaptor proteins or kinases, can initiate signaling cascades also capable of regulating cytoskeletal dynamics.

therefore, growth-cone steering, process extension and retraction, neurite branching and pruning, and neuronal morphological plasticity and regeneration in the adult nervous system.

\section{GUIDANCE-CUE SIGNALING BEYOND NEURAL DEVELOPMENT}

Although we have emphasized the role of the various guidance molecules in regulating growth and guidance of axons, extensive studies over the past decade have shown that these

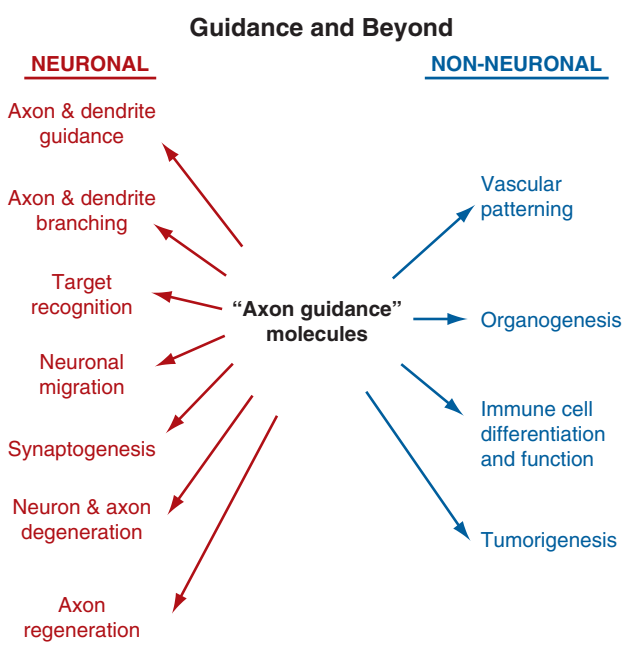

Figure 8. Axon guidance cues serve both neuronal and non-neuronal functions.

molecules have been co-opted to regulate a variety of other processes (Fig. 8). In the nervous system, beyond axon guidance, they regulate neuronal cell migration, axon branching, synapse formation, axon pruning and neuronal cell death, and axonal regeneration. In nonneural systems, they have been co-opted to regulate cell-cell interactions in a variety of systems, including branching morphogenesis in the kidney and lung, vascular patterning, and immune cell migration and recognition. Beyond these functions in normal development and physiology, these molecules have also been implicated in tumorigenesis. Finally, inherited defects in guidance molecules are increasingly being implicated in a variety of neurological disorders (see Engle 2010, this collection). The final articles of this collection (see Adams and Eichmann 2010; Giger et al. 2010; Marin et al. 2010; Shen and Cowan 2010; Vanderhaeghen and Cheng 2010) explore in detail the many functions of guidance molecules beyond axon guidance.

\section{CONCLUSION}

The past two decades have witnessed an explosion of new knowledge about the mechanisms involved in wiring the nervous system and 
how these mechanisms regulate a wide variety of biological phenomena beyond axon guidance, per se. The excellent articles in this collection aim to provide a comprehensive view of the state of the field today, including both the impressive advances that have been made, and the important challenges that remain. We still have a poor understanding of whether additional major guidance-cue families remain to be identified; of the mysteries underlying how growth cones change their responses to cues as they navigate their lengthy trajectories; of the signaling mechanisms that are transduced following receptor activation to direct growth-cone steering; and of just what the limits on axon regrowth and guidance following injury and in disease truly are. Still, based on the rapid progress that has been achieved in a short period of time, we can be guardedly optimistic that significant advances on all these fronts will be achieved in the foreseeable future. It is our hope that this collection will help fuel these advances by providing both new and established investigators with a critical appraisal of the field.

\section{ACKNOWLEDGMENTS}

We thank Fernando Bazan for help with structural assignments for molecular schematics and Allison Bruce for drawing the figures. ALK is supported by the NIH (NINDS, NIMH) and the HHMI, and MTL is supported by Genentech.

\section{REFERENCES}

Andrews GL, Tanglao S, Farmer WT, Morin S, Brotman S, Berberoglu MA, Price H, Fernandez GC, Mastick GS, Charron F, et al. 2008. Dscam guides embryonic axons by Netrin-dependent and -independent functions. Development 135: 3839-3848.

Augsburger A, Schuchardt A, Hoskins S, Dodd J, Butler S. 1999. BMPs as mediators of roof plate repulsion of commissural neurons. Neuron 24: 127-141.

Bashaw GJ, Klein R. 2010. Signaling from axon guidance receptors. Cold Spring Harb Perspect Biol 2: a001941.

Brankatschk M, Dickson BJ. 2006. Netrins guide Drosophila commissural axons at short range. Nat Neurosci 9: 188- 194 .

Brose K, Bland KS, Wang KH, Arnott D, Henzel W, Goodman CS, Tessier-Lavigne M, Kidd T. 1999. Slit proteins bind Robo receptors and have an evolutionarily conserved role in repulsive axon guidance. Cell 96: 795-806.
Chan SS-Y, Zheng H, Su M-W, Wilk R, Killeen MT, Hedgecock EM, Culotti JG. 1996. UNC-40, a C. elegans homolog of DCC (Deleted in Colorectal Cancer), is required in motile cells responding to UNC-6 netrin cues. Cell 87: 187-195.

Charron F, Tessier-Lavigne M. 2007. The Hedgehog, TGFbeta/BMP and Wnt families of morphogens in axon guidance. Adv Exp Med Biol 621: 116-133.

Charron F, Stein E, Jeong J, McMahon AP, Tessier-Lavigne M. 2003. The morphogen sonic hedgehog is an axonal chemoattractant that collaborates with netrin-1 in midline axon guidance. Cell 113: 11-23.

Chen Z, Gore BB, Long H, Ma L, Tessier-Lavigne M. 2008. Alternative splicing of the Robo3 axon guidance receptor governs the midline switch from attraction to repulsion. Neuron 58: 325-332.

Colamarino SA, Tessier-Lavigne M. 1995. Netrin-1 is a bifunctional axon guidance cue: Long range repulsion of trochlear motor axons. Cell 81: 621-629.

Colavita A, Krishna S, Zheng H, Padgett RW, Culotti JG. 1998. Pioneer axon guidance by UNC-129, a C. elegans TGF-beta. Science 281: 706-709.

Deiner MS, Kennedy TE, Fazeli A, Serafini T, Tessier-Lavigne M, Sretavan DW. 1997. Netrin-1 and DCC mediate axon guidance locally at the optic disc: Loss of function leads to optic nerve hypoplasia. Neuron 19: 575-589.

Dent EW, Gertler FB. 2003. Cytoskeletal dynamics and transport in growth cone motility and axon guidance. Neuron 40: 209-227.

Dent EW, Gupton SL, Gertler FB. 2011. How the growth cone moves during axon outgrowth and guidance. Cold Spring Harb Perspect Biol 3: a001800.

Dickson BJ. 2002. Molecular mechanisms of axon guidance. Science 298: 1959-1964.

Ebens A, Brose K, Leonardo ED, Hanson MG Jr, Bladt F, Birchmeier C, Barres BA, Tessier-Lavigne M. 1996. Hepatocyte growth factor/scatter factor is an axonal chemoattractant and a neurotrophic factor for spinal motor neurons. Neuron 17: 1157-1172.

Engle EC. 2010. Human genetic disorders of axon guidance. Cold Spring Harb Perspect Biol 2: a001784.

Fabre PJ, Shimogori T, Charron F. 2010. Segregation of ipsilateral retinal ganglion cell axons at the optic chiasm requires the Shh receptor Boc. J Neurosci 30: 266-275.

Feldheim DA, O'Leary DDM. 2010. Visual map development: Bidirectional signaling, bifunctional guidance molecules, and competition. Cold Spring Harb Perspect Biol 2: a001768.

Giger RJ, Hollis ER II, Tuszynski MH. 2010. Guidance molecules in axon regeneration. Cold Spring Harb Perspect Biol 2: a001867.

Gore BB, Wong KG, Tessier-Lavigne M. 2008. Stem cell factor functions as an outgrowth-promoting factor to enable axon exit from the midline intermediate target. Neuron 57: 501-510.

Hall A, Lalli G. 2010. Rho and Ras GTPases in axon growth, guidance, and branching. Cold Spring Harb Perspect Biol 2: a001818.

Hao JC, Yu TW, Fujisawa K, Culotti JG, Gengyo-Ando K, Mitani S, Moulder G, Barstead R, Tessier-Lavigne M, Bargmann CI. 2001. C. elegans slit acts in midline, 
dorsal-ventral, and anterior-posterior guidance via the SAX-3/Robo receptor. Neuron 32: 25-38.

Harrelson AL, Goodman CS. 1988. Growth cone guidance in insects: fasciclin II is a member of the immunoglobulin superfamily. Science 242: 700-708.

Harris R, Sabatelli LM, Seeger MA. 1996. Guidance cues at the Drosophila CNS midline: Identification and characterization of two Drosophila Netrin/UNC-6 homologs. Neuron 17: 217-228.

Hattori D, Chen Y, Matthews BJ, Salwinski L, Sabatti C, Grueber WB, Zipursky SL. 2009. Robust discrimination between self and non-self neurites requires thousands of Dscam1 isoforms. Nature 461: 644-648.

Hedgecock EM, Culotti JG, Hall DH. 1990. The unc-5, $u n c-6$, and unc-40 genes guide circumferential migrations of pioneer axons and mesodermal cells in the epidermis of C. elegans. Neuron 2: 61-85.

Hong K, Hinck L, Nishiyama M, Poo MM, Tessier-Lavigne M, Stein E. 1999. A ligand-gated association between cytoplasmic domains of UNC5 and DCC family receptors converts netrin-induced growth cone attraction to repulsion. Cell 97: 927-941.

Ishii N, Wadsworth WG, Stern BD, Culotti JG, Hedgecock EM. 1992. UNC-6, a laminin-related protein, guides cell and pioneer axon migrations in C. Elegans. Neuron 9: 873-881.

Keino-Masu K, Masu M, Hinck L, Leonardo ED, Chan SS-Y, Culotti JG, Tessier-Lavigne M. 1996. Deleted in Colorectal Cancer (DCC) encodes a netrin receptor. Cell 87: 175-185.

Keleman K, Dickson BJ. 2001. Short- and long-range repulsion by the Drosophila Unc5 netrin receptor. Neuron 32: 605-617.

Kennedy TE, Serafini T, de la Torre JR, Tessier-Lavigne M. 1994. Netrins are diffusible chemotropic factors for commissural axons in the embryonic spinal cord. Cell 78: 425-435.

Kennedy TE, Wang H, Marshall W, Tessier-Lavigne M. 2006. Axon guidance by diffusible chemoattractants: a gradient of netrin protein in the developing spinal cord. J Neurosci 26: $8866-8874$.

Kidd T, Bland KS, Goodman CS. 1999. Slit is the midline repellent for the Robo receptor in Drosophila. Cell 96: 785-794.

Kidd T, Brose K, Mitchell KJ, Fetter RD, Tessier-Lavigne M, Goodman CS, Tear G. 1998. Roundabout controls axon crossing of the CNS midline and defines a novel subfamily of evolutionarily conserved guidance receptors. Cell 92: 205-215.

Kitsukawa T, Shimizu M, Sanbo M, Hirata T, Taniguchi M, Bekku Y, Yagi T, Fujisawa H. 1997. Neuropilin-semaphorin III/D-mediated chemorepulsive signals play a crucial role in peripheral nerve projection in mice. Neuron 19: 995-1005.

Klein R. 2004. Eph/ephrin signaling in morphogenesis, neural development and plasticity. Curr Opin Cell Biol 16: $580-589$.

Koch M, Murrell JR, Hunter DD, Olson PF, Jin W, Keene DR, Brunken WJ, Burgeson RE. 2000. A novel member of the netrin family, beta-netrin, shares homology with the beta chain of laminin: Identification, expression, and functional characterization. J Cell Biol 151: 221-234.

Kolodkin AL, Matthes D, O'Connor T, Patel NH, Admon A, Bentley D, Goodman CS. 1992. Fasciclin IV: Sequence, expression, and function during growth cone guidance in the grasshopper embryo. Neuron 9: 831-835.

Kolodziej PA, Timpe LC, Mitchell KJ, Fried SR, Goodman CS, Jan LY, Jan YN. 1996. frazzled encodes a Drosophila member of the DCC immunoglobulin subfamily and is required for CNS and motor axon guidance. Cell 87: 197-204.

Kramer ER, Knott L, Su F, Dessaud E, Krull CE, Helmbacher F, Klein R. 2006. Cooperation between GDNF/Ret and ephrinA/EphA4 signals for motor-axon pathway selection in the limb. Neuron 50: 35-47.

Leonardo ED, Hinck L, Masu M, Keino-Masu K, Ackerman SL, Tessier-Lavigne M. 1997. Vertebrate homologues of C. elegans UNC-5 are candidate netrin receptors. Nature 386: $833-838$.

Leung-Hagesteijn C, Spence AM, Stern BD, Zhou Y, Su M-W, Hedgecock EM, Culotti JG. 1992. UNC-5, a transmembrane protein with immunoglobulin and thrombospondin type I domains, guides cell and pioneer axon migrations in C. elegans. Cell 71: 289-299.

Li HS, Chen JH, Wu W, Fagaly T, Zhou L, Yuan W, Dupuis S, Jiang ZH, Nash W, Gick C, et al. 1999. Vertebrate slit, a secreted ligand for the transmembrane protein roundabout, is a repellent for olfactory bulb axons. Cell 96: 807-818.

Lin DM, Goodman CS. 1994. Ectopic and increased expression of fasciclin II alters motoneuron growth cone guidance. Neuron 13: 507-523.

Lin DM, Fetter RD, Kopczynski C, Grenningloh G, Goodman CS. 1994. Genetic analysis of fasciclin II in Drosophila: Defasciculation, refasiculation, and altered fasciculation. Neuron 13: 1055-1069.

Lopez-Bendito G, Cautinat A, Sanchez JA, Bielle F, Flames N, Garratt AN, Talmage DA, Role LW, Charnay P, Marin $\mathrm{O}$, et al. 2006. Tangential neuronal migration controls axon guidance: A role for neuregulin-1 in thalamocortical axon navigation. Cell 125: 127-142.

Lowery LA, Van Vactor D. 2009. The trip of the tip: Understanding the growth cone machinery. Nat Rev Mol Cell Biol 10: 332-343.

Luo Y, Raible D, Raper JA. 1993. Collapsin: a protein in brain that induces the collapse and paralysis of neuronal growth cones. Cell 75: 217-227.

Ly A, Nikolaev A, Suresh G, Zheng Y, Tessier-Lavigne M, Stein E. 2008. DSCAM is a netrin receptor that collaborates with DCC in mediating turning responses to netrin-1. Cell 133: 1241-1254.

Lyuksyutova AI, Lu CC, Milanesio N, King LA, Guo N, Wang Y, Nathans J, Tessier-Lavigne M, Zou Y. 2003. Anterior-posterior guidance of commissural axons by Wnt-frizzled signaling. Science 302: 1984-1988.

Ma L, Tessier-Lavigne M. 2007. Dual branch-promoting and branch-repelling actions of Slit/Robo signaling on peripheral and central branches of developing sensory axons. J Neurosci 27: 6843-6851.

MacNeil LT, Hardy WR, Pawson T, Wrana JL, Culotti JG. 2009. UNC-129 regulates the balance between UNC-40 
A.L. Kolodkin and M. Tessier-Lavigne

dependent and independent UNC-5 signaling pathways. Nat Neurosci 12: 150-155.

Mann F, Chauvet S, Rougon G. 2007. Semaphorins in development and adult brain: Implication for neurological diseases. Prog Neurobiol 82: 57-79.

Marín O, Valiente M, Ge X, Tsai L-H. 2010. Guiding neuronal cell migrations. Cold Spring Harb Perspect Biol 2: a001834.

Mitchell KJ, Doyle JL, Serafini T, Kennedy TE, TessierLavigne M, Goodman CS, Dickson BJ. 1996. Genetic analysis of netrin genes in Drosophila: Netrins guide CNS commissural axons and peripheral motor axons. Neuron 17: 203-215.

Moore SW, Tessier-Lavigne M, Kennedy TE. 2007. Netrins and their receptors. Adv Exp Med Biol 621: 17-31.

Nern A, Zhu Y, Zipursky SL. 2008. Local N-cahderin interactions mediate distinct steps in the targeting of lamina neurons. Neuron 58: 34-41.

Okada A, Charron F, Morin S, Shin DS, Wong K, Fabre PJ, Tessier-Lavigne M, McConnell SK. 2006. Boc is a receptor for sonic hedgehog in the guidance of commissural axons. Nature 444: 369-373.

O'Connor R, Tessier-Lavigne M. 1999. Identification of maxillary factor, a maxillary process-derived chemoattractant for developing trigeminal sensory axons. Neuron 24: $165-178$.

Raper J, Mason C. 2010. Cellular strategies of axonal pathfinding. Cold Spring Harb Perspect Biol 2: a001933.

Sabatier C, Plump AS, Le M, Brose K, Tamada A, Murakami F, Lee EY, Tessier-Lavigne M. 2004. The divergent Robo family protein rig-1/Robo3 is a negative regulator of slit responsiveness required for midline crossing by commissural axons. Cell 117: 157-169.

Salinas PC, Zou Y. 2008. Wnt signaling in neural circuit assembly. Annu Rev Neurosci 31: 339-358.

Sanchez-Camacho C, Bovolenta P. 2008. Autonomous and non-autonomous Shh signalling mediate the in vivo growth and guidance of mouse retinal ganglion cell axons. Development 135: 3531-3541.

Schmucker D, Clemens JC, Shu H, Worby CA, Xiao J, Muda M, Dixon JE, Zipursky SL. 2000. Drosophila Dscam is an axon guidance receptor exhibiting extraordinary molecular diversity. Cell 101: 671-684.

Serafini T, Colamarino SA, Leonardo ED, Wang H, Beddington R, Skarnes W, Tessier-Lavigne M. 1996. Netrin-1 is required for commissural axon guidance in the developing vertebrate nervous system. Cell 87: 1001-1014.

Serafini T, Kennedy T, Galko M, Mirzayan C, Jessell T, Tessier-Lavigne M. 1994. The netrins define a family of axon outgrowth-promoting proteins with homology to C. Elegans UNC-6. Cell 78: 409-424.

Shen K, Cowan CW. 2010. Guidance molecules in synapse formation and plasticity. Cold Spring Harb Perspect Biol 2: a001842.

Shirasaki R, Lewcock JW, Lettieri K, Pfaff SL. 2006. FGF as a target-derived chemoattractant for developing motor axons genetically programmed by the LIM code. Neuron 50: $841-853$.

Siebert M, Banovic D, Goellner B, Aberle H. 2009. Drosophila motor axons recognize and follow a
Sidestep-labeled substrate pathway to reach their target fields. Genes Dev 23: 1052-1062.

Spitzweck B, Brankatschk M, Dickson BJ. 2010. Distinct protein domains and expression patterns confer divergent axon guidance functions for Drosophila Robo receptors. Cell 140: 409-420.

Srinivasan K, Strickland P, Valdes A, Shin GC, Hinck L. 2003. Netrin- $1 /$ neogenin interaction stabilizes multipotent progenitor cap cells during mammary gland morphogenesis. Dev Cell 4: 371-382.

Tamagnone L, Comoglio PM. 2000. Signalling by semaphorin receptors: Cell guidance and beyond. Trends Cell Biol 10: 377-383.

Tessier-Lavigne M, Goodman CS. 1996. The molecular biology of axon guidance. Science 274: 1123-1133.

Tessier-Lavigne M, Placzek M, Lumsden AGS, Dodd J, Jessell TM. 1988. Chemotropic guidance of developing axons in the mammalian central nervous system. Nature 336: 775-778.

Tran TS, Kolodkin AL, Bharadwaj R. 2007. Semaphorin regulation of cellular morphology. Annu Rev Cell Dev Biol 23: 263-292.

Trousse F, Marti E, Gruss P, Torres M, Bovolenta P. 2001. Control of retinal ganglion cell axon growth: A new role for Sonic hedgehog. Development 128: 3927-3936.

Vanderhaegen P, Cheng H-J. 2010. Guidance molecules in axon pruning and cell death. Cold Sping Harb Perspect Biol 2: a001859.

Wadsworth WG, Bhatt H, Hedgecock EM. 1996. Neuroglia and pioneer neurons express UNC-6 to provide global and local netrin cues for guiding migrations in C. elegans. Neuron 16: 35-46.

Wang KH, Brose K, Arnott D, Kidd T, Goodman CS, Henzel W, Tessier-Lavigne M. 1999. Biochemical purification of a mammalian Slit protein as a positive regulator of sensory axon elongation and branching. Cell 96: 771-784.

Whitford KL, Dijkhuizen P, Polleux F, Ghosh A. 2002. Molecular control of cortical dendrite development. Annu Rev Neurosci 25: 127-149.

Wojtowicz WM, Wu W, Andre I, Qian B, Baker D, Zipursky SL. 2007. A vast repertoire of Dscam binding specificities arises from modular interactions of variable Ig domains. Cell 130: 1134-1145.

Yamauchi K, Phan KD, Butler SJ. 2008. BMP type I receptor complexes have distinct activities mediating cell fate and axon guidance decisions. Development 135: 1119-1128.

Yazdani U, Terman JR. 2006. The semaphorins. Genome Biol 7: 211.

Yoshikawa S, McKinnon RD, Kokel M, Thomas JB. 2003. Wnt-mediated axon guidance via the Drosophila Derailed receptor. Nature 422: 583-588.

Zallen J, Yi BA, Bargmann CI. 1998. The conserved immunoglobulin superfamily member SAX-3/Robo direts multiple aspects of axon guidance in C. Elegans. Cell 92: $217-227$.

Zhou Y, Gunput RA, Pasterkamp RJ. 2008. Semaphorin signaling: Progress made and promises ahead. Trends Biochem Sci 33: 161-170. 


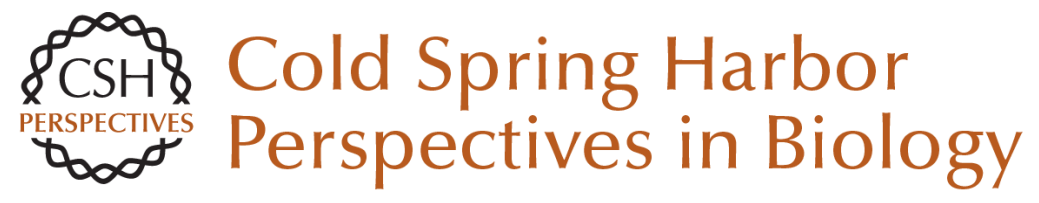

\section{Mechanisms and Molecules of Neuronal Wiring: A Primer}

Alex L. Kolodkin and Marc Tessier-Lavigne

Cold Spring Harb Perspect Biol 2011; doi: 10.1101/cshperspect.a001727 originally published online December 1, 2010

\section{Subject Collection Neuronal Guidance}

Mechanisms and Molecules of Neuronal Wiring: A Primer

Alex L. Kolodkin and Marc Tessier-Lavigne

Guidance Molecules in Axon Pruning and Cell

Death

Pierre Vanderhaeghen and Hwai-Jong Cheng

Initiating and Growing an Axon

F. Polleux and William Snider

Navigating Intermediate Targets: The Nervous System Midline

Barry J. Dickson and Yimin Zou

Cellular Strategies of Axonal Pathfinding

Jonathan Raper and Carol Mason

Guidance Molecules in Axon Regeneration

Roman J. Giger, Edmund R. Hollis II and Mark H. Tuszynski

Signaling from Axon Guidance Receptors Greg J. Bashaw and Rüdiger Klein

Visual Map Development: Bidirectional Signaling, Bifunctional Guidance Molecules, and Competition

David A. Feldheim and Dennis D. M. O'Leary
Wiring the Brain: The Biology of Neuronal Guidance

Alain Chédotal and Linda J. Richards

Guidance Molecules in Synapse Formation and

Plasticity Kang Shen and Christopher W. Cowan

The Growth Cone Cytoskeleton in Axon

Outgrowth and Guidance

Erik W. Dent, Stephanie L. Gupton and Frank B. Gertler

Topographic Mapping--The Olfactory System Takeshi Imai, Hitoshi Sakano and Leslie B. Vosshall

Self-avoidance and Tiling: Mechanisms of

Dendrite and Axon Spacing Wesley B. Grueber and Alvaro Sagasti

Trafficking Guidance Receptors Bettina Winckler and Ira Mellman

Axon Guidance Molecules in Vascular Patterning Ralf H. Adams and Anne Eichmann

Human Genetic Disorders of Axon Guidance Elizabeth C. Engle

For additional articles in this collection, see http://cshperspectives.cshlp.org/cgi/collection/

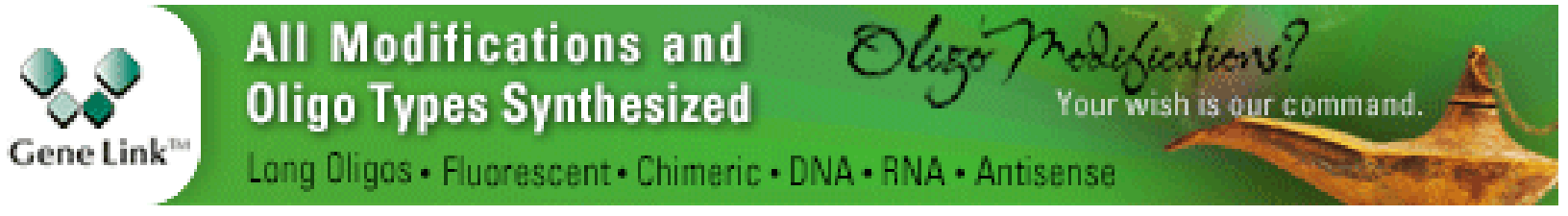

Copyright @ 2011 Cold Spring Harbor Laboratory Press; all rights reserved 